\title{
Sawtooth fetal heart rate pattern associated with a favorable neurological outcome in an infant: a case report
}

\author{
Satoshi Ohira*, Sakura Yamanaka, Ryoichi Asaka, Hirofumi Ando, Chiho Fuseya, Norihiko Kikuchi, \\ Tsutomu Miyamoto, Makoto Kanai and Tanri Shiozawa
}

\begin{abstract}
Background: The sawtooth fetal heart rate pattern is rare, and has been reported as a possible indicator of neurological sequelae in newborns. However, we observed this fetal heart rate pattern in an infant with normal neurological function.

Case presentation: A 29-year-old primigravida Japanese woman presented to our hospital at 40 weeks and 1 day of gestation with marked vaginal bleeding. Since admission, fetal heart rate tracing consistently demonstrated a sawtoothlike pattern. There were 3-4 oscillations per minute, and their amplitude was 30-40 beats per minute. An emergency cesarean section was performed because of non-reassuring fetal status. Evidence of placental abruption was not observed. The newborn was a male weighing $2936 \mathrm{~g}$, with an Apgar score of 1 and 3 at 1 minute and 5 minutes, respectively. The infant received brain cooling, but was discharged uneventfully. A follow-up examination at age 3 years demonstrated no developmental restriction.
\end{abstract}

Conclusion: Although the Apgar score of the newborn was low, the infant had no neurological sequelae. Thus, the sawtooth fetal heart rate pattern may not be linked to in utero irreversible fetal central nervous system injury.

Keywords: Sawtooth fetal heart rate pattern, Fetal heart rate monitoring, Neurological sequelae, Case report

\section{Background}

Antenatal and intrapartum application of electronic fetal heart rate (FHR) monitoring for the evaluation of fetal condition are of common use in developed countries. The efficacy of electronic FHR monitoring during labor is judged by its ability to decrease complications, such as neonatal seizures, cerebral palsy, or intrapartum fetal death, while minimizing the need for unnecessary obstetric interventions $[1,2]$. Despite well-designed basic science investigations into the physiology underlying standard FHR patterns (variability, accelerations, and decelerations), these observations have not translated into measurable positive impacts on newborn outcomes but have contributed significantly to the cesarean delivery rate [3-7]. Recently, Andrikopoulou and Vintzileos [8] reported three cases of documented central nervous

\footnotetext{
* Correspondence: osatoshi@shinshu-u.ac.jp

Department of Obstetrics and Gynecology, Shinshu University School of Medicine, 3-1-1 Asahi, Matsumoto 390-8621, Japan
}

system (CNS) injury with a characteristic FHR sawtoothlike pattern. However, we observed this FHR pattern in an infant with normal neurological function. Here we report a case of sawtooth FHR pattern associated with a favorable neurological outcome in an infant.

\section{Case presentation}

A 29-year-old primigravida Japanese woman presented to our hospital at 40 weeks and 1 day of gestation with marked vaginal bleeding. The posterior placenta had been low-lying, but had migrated to the upper uterine segment in the third trimester. Since admission, FHR tracing consistently demonstrated a sawtooth-like pattern with indeterminate baseline (Fig. 1). There were 3-4 sharp oscillations per minute, and their amplitude was 30-40 beats per minute (bpm) (Fig. 2). Although fetal movement was slightly observed, only a small amount of amniotic fluid was noted by ultrasonography. The middle cerebral artery peak systolic velocity of the fetus

(c) The Author(s). 2019 Open Access This article is distributed under the terms of the Creative Commons Attribution 4.0 International License (http://creativecommons.org/licenses/by/4.0/), which permits unrestricted use, distribution, and 


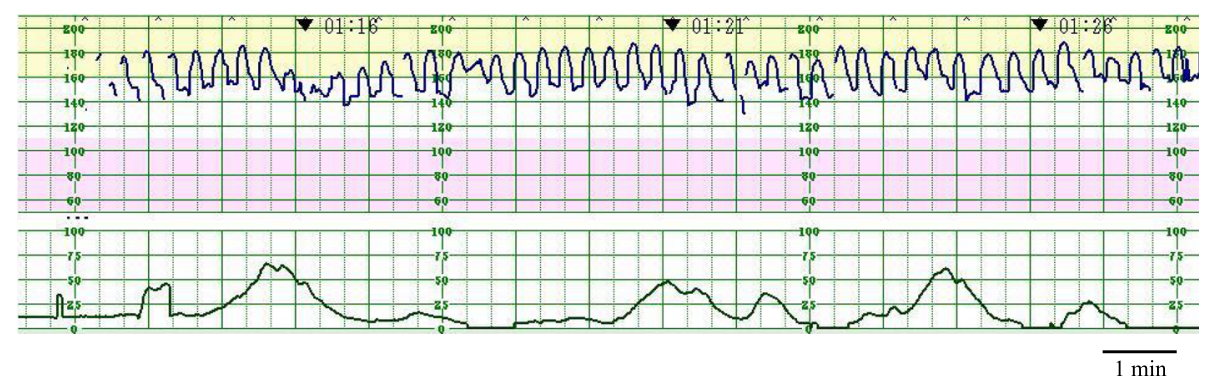

Fig. 1 Sawtooth pattern tracings with indeterminate baseline

was $100 \mathrm{~cm} /$ second $(1.55$ multiples of the median); therefore, we initially suspected fetal anemia.

Emergency cesarean section was performed because of non-reassuring fetal status. Evidence of placental abruption was not observed. The newborn was a male weighing $2936 \mathrm{~g}$, with an Apgar score of 1 and 3 at 1 minute and 5 minutes, respectively. The umbilical artery cord $\mathrm{pH}$ was not available because the artery collapsed. The newborn was not severely anemic, with a hemoglobin level of 13.3 $\mathrm{g} / \mathrm{dl}$. The venous blood $\mathrm{pH}$ was 6.860 and base excess was - 21.9. Sarnat staging for hypoxic-ischemic encephalopathy [9] of this newborn was grade II moderate. Therefore, the infant received brain cooling for 72 hours from 4 hours after birth. No abnormal findings were detected by brain magnetic resonance imaging performed at 13 days after birth, and the infant was discharged uneventfully. A follow-up examination including DENVER II Developmental Screening Test [10] at age 1, 2, and 3 years demonstrated no developmental restriction.

\section{Discussion}

The sawtooth FHR pattern is rare, and is sometimes confused with sinusoidal pattern [8]. This FHR pattern is characterized by the following: (1) three to five sawtoothlike sharp oscillations per minute; (2) amplitude $>20 \mathrm{bpm}$; and (3) unstable or indeterminate baseline [8]. On the other hand, true sinusoidal FHR pattern is characterized by the following: (1) stable baseline FHR of $120-160 \mathrm{bpm}$; (2) amplitude of $5-15 \mathrm{bpm}$; (3) frequency of $2-5$ cycles per minute; (4) fixed or flat short-term variability; (5)

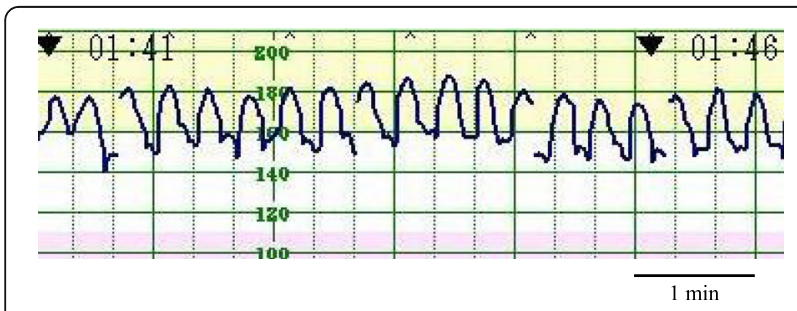

Fig. 2 There are 3-4 sharp oscillations per minute, and the amplitude is $30-40$ beats per minute oscillations of the sinusoidal wave form above and below a baseline; and (6) no area of normal FHR variability or reactivity $[11,12]$. The FHR pattern in our case demonstrated 3-4 oscillations per minute, amplitude of 30-40 bpm, and indeterminate baseline; therefore, the FHR pattern in our case is consistent with the abovedescribed features of the sawtooth FHR pattern.

Other than true sinusoidal FHR pattern, another conventional undulating FHR pattern may be due to pseudosinusoidal FHR pattern $[11,13]$. Pseudo-sinusoidal FHR patterns include all patterns in which undulatory waveforms, or regular FHR baseline oscillations of constant amplitude, alternate with episodes of normal baseline variability or activity [13]. Murphy et al. observed 230 pseudosinusoidal FHR patterns in labor, and classified 219 into minor (amplitude 5-15 bpm) and 11 into intermediate (amplitude 16-24 bpm) [13]. Major pseudo-sinusoidal patterns (amplitude $>24 \mathrm{bpm}$ ) were not observed [13]. Before the sawtooth FHR pattern was proposed, our case might be considered to be a major pseudo-sinusoidal pattern because of large amplitude.

Andrikopoulou and Vintzileos reported three cases of sawtooth FHR pattern due to in utero fetal CNS injury [8]. In their first case, there was a sudden onset of sawtooth FHR pattern during labor. The Apgar score after a vaginal delivery was 9 and 9 at 1 minute and 5 minutes, respectively. Magnetic resonance imaging of the newborn, which was performed because of facial twitches, showed infarction of the left cerebral hemisphere because of a middle cerebral artery thrombosis. The approximate timing of the fetal stroke coincided with the abrupt onset of the sawtooth FHR pattern in labor. In their second case, the patient was admitted with sawtooth FHR pattern. Emergency cesarean section was performed and the Apgar score was 0 and 3 at 1 minute and 5 minutes, respectively. An electroencephalogram was abnormal, and the infant received brain cooling but unfortunately died. The third case had sawtooth FHR pattern during the second stage of labor, and the Apgar score was 3 and 6 at 1 minute and 5 minutes, respectively. A cranial ultrasound of the neonate revealed grade II intraventricular hemorrhage. 
In our case, the Apgar score of the newborn was low, but the infant had no neurological sequelae. Although the reason why the sawtooth FHR pattern appeared is unclear, we speculate that transient fetal asphyxia was caused by circulatory failure of the placenta due to marked hemorrhage from placental margin.

\section{Conclusions}

This is the first report of sawtooth FHR pattern without fetal CNS injury. Thus, this FHR pattern may not be linked to in utero irreversible fetal CNS injury. Further studies are needed to clarify the pathology underlying sawtooth FHR pattern.

\section{Acknowledgements}

The authors are grateful to Keiya Fujimori (Department of Obstetrics and Gynecology, School of Medicine, Fukushima Medical University) for the advisement in this case.

\section{Authors' contributions}

SO, SY, RA, HA, CF, and NK were in charge of this pregnant woman. TM, MK, and TS helped to draft the manuscript. All authors read and approved the final manuscript.

\section{Funding}

Not applicable.

\section{Availability of data and materials}

Not applicable.

\section{Ethics approval and consent to participate}

The study was sent to the ethical committee of Shinshu University School of Medicine and need for approval was waived.

\section{Consent for publication}

Written informed consent was obtained from the patient's legal guardian for publication of this case report and any accompanying images. A copy of the written consent is available for review by the Editor-in-Chief of this journal.

\section{Competing interests}

The authors declare that they have no competing interests.

Received: 4 December 2018 Accepted: 20 June 2019

Published online: 25 July 2019

\section{References}

1. American College of Obstetricians and Gynecologists. ACOG Practice Bulletin No.62: Intrapartum fetal heart rate monitoring. Obstet Gynecol. 2005;105:1161-9.

2. Freeman RK. Problems with intrapartum fetal heart rate monitoring interpretation and patient management. Obstet Gynecol. 2002;100:813-26.

3. Clark SL, Meyers JA, Frye DK, Garthwaite T, Lee AJ, Perlin JB. Recognition and response to electronic fetal heart rate patterns: impact on newborn outcomes and primary cesarean delivery rate in women undergoing induction of labor. Am J Obstet Gynecol. 2015;212:494.e1-6.

4. Williams RL, Hawes WE. Cesarean section, fetal monitoring, and perinatal mortality in California. Am J Public Health. 1979;69:864-70.

5. Haverkamp AD, Thompson HE, McFee JG, Cetrulo C. The evaluation of continuous fetal heart rate monitoring in high risk pregnancy. Am J Obstet Gynecol. 1976;125:310-20.

6. Haverkamp AD, Orleans M, Langendoerfer S, MCFee J, Murphy J, Thompson HE. A controlled trial of the differential effects of intrapartum fetal monitoring. Am J Obstet Gynecol. 1979;134:399-412.

7. Renou P. Warwick N, Wood C. Autonomic control of fetal heart rate. Am J Obstet Gynecol. 1969;105:949-53.
8. Andrikopoulou M, Vintzileos AM. Sawtooth fetal heart rate pattern due to in utero fetal central nervous system injury. Am J Obstet Gynecol. 2016;214:403.e1-4.

9. Sarnat H, Sarnat M. Neonatal encephalopathy following fetal distress. Arch Neurol. 1976;33:695-705

10. Frankenburg WK, Dodds J, Archer P, Shapiro H, Bresnick B. The Denver II: a major revision and restandardization of the Denver Developmental Screening Test. Pediatrics. 1992;89:91-7.

11. Modanlou HD, Murata Y. Sinusoidal heart rate pattern: reappraisal of its definition and clinical significance. J Obstet Gynaecol Res. 2004;30:169-80.

12. Modanlou HD, Freedman RK. Sinusoidal heart rate pattern: its definition and clinical significance. Am J Obstet Gynecol. 1982;142:1033-8.

13. Murphy KW, Russell V, Collins A, Johnson P. The prevalence, aetiology and clinical significance of pseudo-sinusoidal fetal heart rate patterns in labour. Br J Obstet Gynaecol. 1991;98:1093-101.

\section{Publisher's Note}

Springer Nature remains neutral with regard to jurisdictional claims in published maps and institutional affiliations.

Ready to submit your research? Choose BMC and benefit from:

- fast, convenient online submission

- thorough peer review by experienced researchers in your field

- rapid publication on acceptance

- support for research data, including large and complex data types

- gold Open Access which fosters wider collaboration and increased citations

- maximum visibility for your research: over $100 \mathrm{M}$ website views per year

At $\mathrm{BMC}$, research is always in progress.

Learn more biomedcentral.com/submission 